\title{
THE INFESTATION OF FUNGUS CULTURES BY MITES'
}

\section{(ITS NATURE AND CONTROL TOGETHER WTTH SOME REMARKS ON THE TOXIC PROPERTIES OF PYRIDINE)}

By SIBYL T. JEWSON, M.Sc.

(Department of Mycology, Rothamsted Experimental Station, Harpenden), AND F. TATTERSFIELD, B.Sc., F.I.C.

(Rothamsted Experimental Station).

(With 4 Text-figures.)

\section{CONTENTS.}

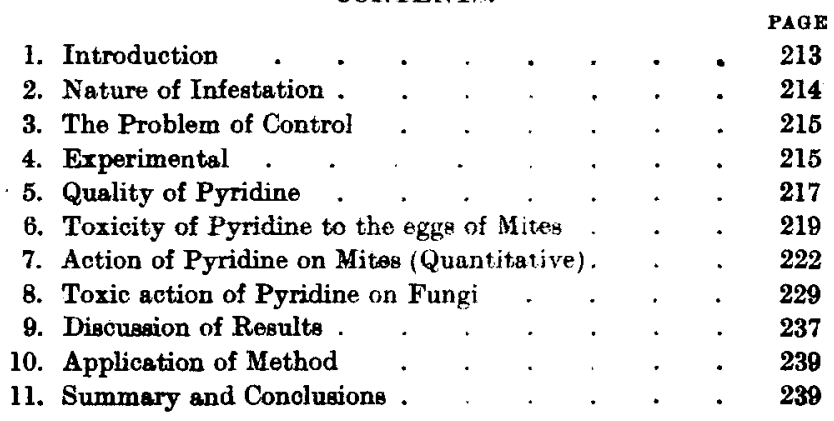

\section{Introduction.}

THE infestation of pure cultures of fungi by mites is a considerable source of trouble in mycological laboratories. This difficulty having arisen at Rothamsted, it was considered advisable to make a careful study of the nature of the infestation and the toxic effect of a number of volatile organic chemical compounds on these pests and on fungi. The object of the investigation was to find a method of controlling the mite infection without injuring the fungi. Once having gained acress to the laboratory

1 A grant in aid of publication has been received for this communioation. 
mites make their way through cotton-wool plugs of culture tubes. Besides destroying the culture they have entered, they may make accurate subculturing a matter of difficulty by reason of the extraneous matter -bacteria, fungus spores, etc.-they carry with them into the tube. They wander rapidly from tube to tube and, unless discovered at an early stage, the whole set of cultures in a laboratory may be either destroyed or seriously contaminated. Even if the cultures be abandoned and a completely fresh start made, another infestation may readily take place from eggs laid in some unnoticed corner of the laboratory.

\section{Nature of the INfestation.}

Three species of mites were found contaminating cultures of which Aleurobius farinae, De Geer, the Flour Mite, was the most abundant and widespread. In many cases infection was slight; in others eggs, larvae and adults were present but the mycelium was not noticeably destroyed by this species. Tyroglyphus longior, Gervais, one of the cheese mites, was observed in a few cultures. In most cases infection by this species was very slight, but in three cultures of a species of the fungus Trichoderma the whole of the fungus was destroyed and the medium was blackened with faecal pellets. Glyciphagus cadaverum, Schrank, was found only in one set of cultures. The eggs of the two latter species were not recorded. These three species are among those termed "Forage Mites" as distinguished from "Mange Mites." They infect many kinds of grain and flour and can frequently be found in the dust from crevices in houses or stables. T. longior and A. farinae are also two of the species that attack Stilton and Cheddar cheeses. The life histories of all three species are very similar, consisting of four stages, egg, larva, nymph and adult. That of $T$. longior has been described by Eales(1). The life cycle is completed in four to five weeks, the eggs hatching about 10-12 days after being laid. The larva is distinguished from the later stages by having only three pairs of legs. It feeds actively for about a week, then becomes quiescent and casts its skin, emerging as the first nymph. This moults and becomes the second nymph which after a third moult emerges as an adult male or female. There may, under favourable conditions, be an additional hypopial stage, the hypopus being specially adapted for distribution. It has a resistant skin and on the ventral surface there is a sucker by which it can attach itself to flies, moths or human beings. The life cycle of $A$. farinae as described by Newstead and Duvall(2) is very similar but usually shorter, varying from about 17 days in July to 28 days in the winter months. The eggs usually hatch in about 3-4 days. There is only one nymphal stage and the hypopus is very rare. G. cadaverum has a similar life history but the details are not well known. 


\section{The Problem of Control.}

The sine qua non of any method of control is that the treatment should kill 100 per cent. of the mites and their eggs and have a minimum detrimental effect upon the fungus cultures. It should not be harmful to the operator and it should be easy to apply. If a chemical method is to be used it is essential that the substance be volatile, not too disagreeable, and that in its toxic action it should be reasonably speedy. In flour mills it is customary to keep mites under control by scrupulous cleanliness and where necessary by the application of heat. The lowest lethal temperature was found by Newstead and Duvall(2) to be $49^{\circ} \mathrm{C}$. applied for at least 12 hours. This latter method was not available in our case as the temperatures likely to be effective against the parasite would have a seriously detrimental action upon the fungus culture. A fairly extensive list of volatile organic compounds was therefore tried and their effect studied upon mites and their eggs and upon fungi.

Ammonia was found to be the most rapidly toxic substance to mites and their eggs. It had, however, a definite toxic action on fungi and although it may prove of great value for ridding laboratory apparatus, such as incubators, of these pests, its vapour should not be allowed to play upon the cultures of fungi for any length of time.

Pyridine was the next most rapidly toxic compound tested and although it is many times less toxic than ammonia vapour, it has the added advantage of not being poisonous to fungi, except in doses not likely to occur in practice. As its vapour is rather disagreeable it is hardly suitable for the purposes for which ammonia is recommended, but for freeing fungus cultures of mite pests it can be so easily applied that it should not prove in any way obnoxious to the operator. A detailed description of both methods is given on p. 239.

\section{EXPERIMERTAL.}

The compounds tested were:

Ammonia bases $\left\{\begin{array}{l}\text { Ammonia } \\ \text { Pyridine } \\ \text { Aniline } \\ \text { Monomethylaniline } \\ \text { Dimethylaniline }\end{array}\right.$
Aromatic
hydrocarbons


All these compounds were chosen because of their definite insecticidal value. With the exception of Ammonia, Mono- and Dimethylaniline this is not considerable but it was thought to be sufficiently high for the substances to prove effective in air saturated with their vapour against a not very resistant pest. Moreover, it was considered that the toxic effect of the majority of them to fungi would be small.

\section{(a) Action upon Fungi.}

As it was essential that the latter condition should be complied with, these substances were all given a preliminary test to discover their action against a common fungus. A green Penicilliam was used, the cultures being tested in duplicate, one of each couple being exposed with the cotton-wool plug in situ, the other with it removed ${ }^{1}$. The culture tubes were put into a large boiling tube containing a quantity of the chemical, sufficient to saturate the air with its vapour. The boiling tube was then corked and put aside for three days after which the culture was taken out and subcultured. The results are stated in Table $\mathrm{I}$.

Table I.

Effect of Vapour of various Organic Chemicals on Penicillium sp. Culture exposed for three days and then subcultured.

\begin{tabular}{ll}
\multicolumn{1}{c}{ Chemical } & \multicolumn{1}{c}{ Growth of subculture after 7 days } \\
1. Ammonia & No growth \\
2. Pyridine & Good growth \\
3. Aniline & $"$ \\
4. Monomethylaniline & $"$ \\
5. Dimethylaniline & $"$ \\
6. Benzene & Fairly good growth \\
7. Toluene & Good growth \\
8. Naphthalene & Good growth \\
9. p-Dichlorbenzene & One fair growth and one slight growth \\
10. Carbon tetrachloride & No growth \\
11. Carbon bisulphide &
\end{tabular}

(b) Action upon Mites.

A selection of the above compounds was then tested upon mites. Some flour mites, A. farinae, were placed in tubes which were vaselined round the outer lip to prevent the escape of the mites, but left unplugged. Exposure to the toxic substance was made in exactly the same way as described but for varying lengths of time. The results are shown in Table II.

2 The results of the two eeries showed no significent differences. 
Table II.

Action of the Vapour of Certain Organic Chemical Compounds on Mites (Aleurobius farinae).

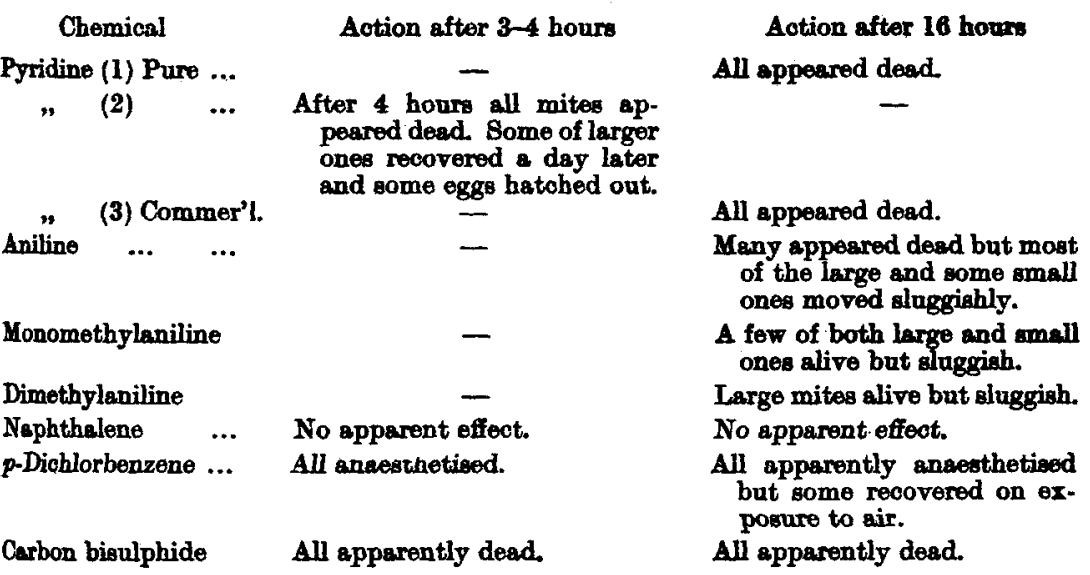

An inspection of Tables I and II clearly indicates that for practical purposes Pyridine is much the most hopeful compound. Carbon bisulphide, although apparently rapid in its action, is too toxic to fungi to be useful, while Paradichlorbenzene, which, from its slight poisonous action on fungi and from the almost complete absence of disagreeable properties, would have been an ideal substance to apply, seems to have only a pronounced but temporary anaesthetic effect.

In view of these results it was decided to make a more complete study of the toxic action of Pyridine and to ascertain, if possible in a quantitative way, its reaction with both mites and some common fungus.

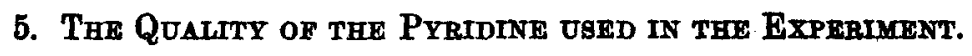

Four samples of Pyridine were tested for their effect upon mites and fungi.

1. A sample labelled pure Pyridine.

2. A sample obtained by a rough fractionation of commercial Pyridine.

3. Commercial Pyridine.

4. A sample carefully purified in the Laboratory.

No. 2 sample was intermediate in quality between samples 1 and 3.

The testing of these grades was regarded as necessary owing to the wide discrepancy in price between pure and commercial Pyridine. It was also essential to ascertain whether through the presence of any 
impurity commercial Pyridine would prove deleterious to fungi and so inhibit its use or render its fractionation and purificstion indispensable. Moreover, it was important to ascertain whether the actual toxic product in the commercial article was Pyridine itself or some impurity.

For purposes of reference and comparison the specific gravity and the fractions distilling at various temperatures were determined.

The distillations were carried out in the following way:

75 c.c. were distilled at a rate of one drop per second from a 150 c.c. flask (neck $9 \mathrm{~cm}$. long, diameter of bulb $6.5 \mathrm{~cm}$.) fitted with a four-pear fractionating column of a length from bottom to side tube of $24.5 \mathrm{~cm}$.

The column was so adjusted into the neck of the flask that the total length of still-hesd was just about $30 \mathrm{~cm}$. A Davies double jacketed condenser in a perpendicular position was attached to the side tube of the column. The distillates were collected and measured. The results are tabulated in Table III.

Table III.

Fractional Distillation of Three Samples of Pyridine. 75 c.c. distilled at a rate of 1 drop per second.

\begin{tabular}{|c|c|c|c|c|c|c|c|c|c|c|}
\hline \multicolumn{3}{|c|}{$\begin{array}{l}\text { le of Pyridine labelled Pure. } \\
\text { 3.G. at } 15.5^{\circ} \mathrm{C} ., 1-0098\end{array}$} & \multicolumn{4}{|c|}{$\begin{array}{l}\text { Crude Pyridine fraotion from Com- } \\
\text { mercial Pyridine. S.G. at } 15 \cdot 5^{\circ} \mathrm{C} \text {, } \\
\text { l-0092 }\end{array}$} & \multicolumn{4}{|c|}{$\begin{array}{l}\text { Commercial Pyridina } \\
\text { S.G. at } 15 \cdot 5^{\circ} \text { C., 0-99307 }\end{array}$} \\
\hline Temp. & $\begin{array}{c}\text { Vol. of } \\
\text { distillste }\end{array}$ & $\begin{array}{c}\% \text { of } \\
\text { distillate }\end{array}$ & No. & $\begin{array}{l}\text { Temp. } \\
\text { o.C. }\end{array}$ & $\begin{array}{l}\text { Vol of } \\
\text { distillate }\end{array}$ & $\begin{array}{c}\% \text { of } \\
\text { digtillate }\end{array}$ & No. & $\begin{array}{l}\text { Temp. } \\
{ }^{\circ} \mathrm{C} .\end{array}$ & Vol of & diatillate \\
\hline 92 & lst drop & & & 88 & lst drop & & & 94 & lst drop & \\
\hline 92-110 & 0.2 c.c. & $\cdot 27$ & 1. & $88-110$ & 3.5 c.c & $4 \cdot 67$ & $1 a$. & 94-100 & 30 c.c. & 400 \\
\hline & & & & & & & $1 \boldsymbol{b}$ & $100-110$ & $5 \cdot 3$ & 7.07 \\
\hline $110-115$ & 1.3 & $1 \cdot 73$ & 2. & $110-120$ & $13 \cdot 5$ & $18-00$ & $2 a$. & $110-115$ & $2-0$ & $2-67$ \\
\hline $115-120$ & $25 \cdot 0$ & $33-34$ & & & & & $2 b$. & $115-120$ & 4.0 & $6 \cdot 33$ \\
\hline $120-125$ & $30 \cdot 0$ & 40.0 & $3 a$. & $120-125$ & 29.5 & $\mathbf{3 9 \cdot 3 3}$ & $3 a$. & $120-125$ & $16 \cdot 3$ & $21 \cdot 73$ \\
\hline $125-130$ & $8 \cdot 0$ & $10-67$ & $3 b$. & $125-130$ & $10 \cdot 5$ & $14 \cdot 00$ & $3 b$ & $125-130$ & $6 \cdot 9$ & 92 \\
\hline $130-140$ & $7 \cdot 7$ & $10 \cdot 26$ & 4. & $130-140$ & 9-0 & $12 \cdot 0$ & 4 & $130-140$ & 70 & 9.3 \\
\hline Residne & $2 \cdot 8$ & 3.73 & 5. & $140-150$ & $6-5$ & $8 \cdot 67$ & 5. & Residue & $3 \cdot 5$ & $4 \cdot 67$ \\
\hline & & & & Residue & $2 \cdot 5$ & $3 \cdot 33$ & & & & \\
\hline
\end{tabular}

An imspection of this table shows that there are wide differences in the composition of the three samples, that the commercial product (which contains about 34 per cent. water) has a considerable fraction distilling off between $95^{\circ}$ and $100^{\circ} \mathrm{C}$, and that the sample labelled Pure is misrepresented. The last point was confirmed by testing with Permanganate which was rapidly decolourised. In view of the obvious impurity of the Pyridine labelled "Pure," this sample was trested with Potassium Permanganate, dried over solid Caustic Potash and frac- 
tionated. The fraction distilling between $115^{\circ}$ and $125^{\circ} \mathrm{C}$. was again treated with Permanganate and again fractionated. The fraction distilling between $114^{\circ}$ and $117^{\circ} \mathrm{C}$. was collected and tested quantitatively for its toxicity to mites. The pure and commercial Pyridine were tested for their toxic action to mites and their eggs.

Two samples of cheese mites were obtained and identified as $T$. longior, or a species very closely related to it. Both samples contained a large number of eggs. Duplicate tubes of the mites were then treated in belljars with (a) Pyridine ( 1 above), and (b) commercial Pyridine (3 above) for a period of 16 bours, two controls being set aside over water for purposes of comparison. At the end of this period they were examined and in all the treated samples the mites showed no signs of life.

After a period of fourteen days all the samples were re-examined with the result that whereas one of the controls showed many young and lively mites and comparatively few unhatched eggs and the other a few large live mites and a large number of unhatched eggs, the tubes exposed to the vapour of both samples of Pyridine contained no live mites, either adults or newly hatched larvae. This and many subsequent experiments amply proved that there is little or no difference in toxic action between the costly pure Pyridine and the cheap commercial article.

\section{Toxicity of Pyridine to the Eggs of Mites.}

The critical point in the method is the toxicity of Pyridine to the eggs of mites, for unless all are killed the infection is not eliminated. This matter was therefore studied with considerable care, the actual experiments being repeated several times to eliminate chance results due to such factors as the Pyridine not penetrating a thick mass of mites or to the sample undergoing desiccation during the aeration subsequent to the experiment.

The results in one case (Series I) do not agree with those obtained at any other time, but they are set out in Table IV $a$ with the purpose of indicating that a sixteen-hour exposure which we have generally found to be ample to kill all mites and eggs may fail in certain cases and as a consequence we suggest that with very heavy infestations a second exposure may be necessary after a period of fourteen days.

Series $I$ was exposed in duplicate for 16 hours to vapour of three qualities of Pyridine. A little flour was placed in each tube to provide a food supply for any larvae hatching out. After treatment both mites and flour were transferred to fresh tubes and the excess of Pyridine allowed to escape. The result was definitely negative and might be due 
either to the cold weather prevailing at the time diminishing the concentration of Pyridine in the air of the bell-jar, or to the eggs being rather more resistant in this case or under these conditions.

Series II was exposed to the vapour of commercial Pyridine for two different periods, 16 and 48 hours, in each case in duplicate. The samples were then transferred to Petri dishes and exposed to the moist air of a warm greenhouse for eight hours to free the material from traces of Pyridine as completely and rapidly as possible. The samples were then transferred back to tubes and allowed to stand in a damp atmosphere for 16 to 19 days, small portions being examined from time to time.

The results of both series are shown in Table IV $a$.

Table IV $a$.

Showing effect of Pyridine upon Mites and Eggs. (Sample contained about equal numbers of each.)

Series I.

Set on $18 / 1 / 22$.

Exposure to Vapour of Pyridine for 16 hours.

\begin{tabular}{|c|c|c|c|c|c|c|}
\hline Examined & $\begin{array}{l}\text { Days } \\
\text { after } \\
\text { taking } \\
\text { off }\end{array}$ & Cont & & $\begin{array}{c}\text { Pure Pyridine } \\
\text { (1) }\end{array}$ & $\begin{array}{c}\text { Commercial } \\
\text { Pyridine } \\
\text { fractionated } \\
\text { (2) }\end{array}$ & $\begin{array}{c}\text { Conumercial } \\
\text { Pyridine } \\
\text { (3) }\end{array}$ \\
\hline $19 / 1 / 22$ & $-A$ & Active-a & stages & $\begin{array}{l}\text { Apparently } \\
\text { dead un- } \\
\text { hatched eggs }\end{array}$ & $\begin{array}{l}\text { Apparently } \\
\text { dead un- } \\
\text { hatched egg8 }\end{array}$ & $\begin{array}{l}\text { Apparently } \\
\text { dosd un- } \\
\text { hatched eggs }\end{array}$ \\
\hline $23 / 1 / 22$ & 4 & " & " & $\begin{array}{l}\text { One mature } \\
\text { live mite }\end{array}$ & $\begin{array}{l}\text { Apparently } \\
\text { dead un- } \\
\text { hatched eggs }\end{array}$ & $\begin{array}{l}\text { Apparently } \\
\text { dead un- } \\
\text { hatched eggs }\end{array}$ \\
\hline $27 / 1 / 22$ & 8 & " & " & $\begin{array}{l}\text { One tube app. } \\
\text { dead: second } \\
\text { tube live larvae }\end{array}$ & $\begin{array}{l}\text { Live larrae } \\
\text { (both tubes) }\end{array}$ & $\begin{array}{l}\text { Apparently } \\
\text { dead un- } \\
\text { hatched egga }\end{array}$ \\
\hline $31 / 1 / 22$ & 12 & $"$ & " & $\begin{array}{c}\text { One adult, one } \\
\text { larva; } \\
\text { unhatched eggs }\end{array}$ & $\begin{array}{l}\text { Many larvae; } \\
\text { unhatched eggs }\end{array}$ & $\begin{array}{l}\text { One live larva; } \\
\text { unhatched eggg }\end{array}$ \\
\hline $7 / 2 / 22$ & 19 & $"$ & " & $\begin{array}{l}\text { Eggs, nymphs } \\
\text { and adults }\end{array}$ & $\begin{array}{l}\text { Eggs, nymphs } \\
\text { and adults }\end{array}$ & $\begin{array}{l}\text { Eggs, nymphs } \\
\text { and adults }\end{array}$ \\
\hline
\end{tabular}

Exposure to Vapour of Pyridine for 16 and 48 hours.

Set on 20 and $21 / 2 / 24$.

\begin{tabular}{|c|c|c|c|c|c|c|c|}
\hline \multirow[b]{2}{*}{ Examined } & \multirow{2}{*}{$\begin{array}{l}\text { Days } \\
\text { after } \\
\text { taking } \\
\text { off }\end{array}$} & \multirow{2}{*}{\multicolumn{2}{|c|}{ fontrols }} & \multicolumn{4}{|c|}{ Commercial Pyridine } \\
\hline & & & & \multirow{3}{*}{\multicolumn{2}{|c|}{$\begin{array}{l}\text { Exposure } 16 \mathrm{hrs} \text {. } \\
\text { All apparently dead } \\
\text { No live mites }\end{array}$}} & \multirow{3}{*}{\multicolumn{2}{|c|}{$\begin{array}{l}\text { Exposure } 48 \mathrm{hrs} . \\
\text { All apparently dead } \\
\text { No live mites }\end{array}$}} \\
\hline $22 / 2 / 22$ & - & \multicolumn{2}{|c|}{ Actire-all stages } & & & & \\
\hline $27 / 2 / 22$ & 5 & ,+ & $"$ & & & & \\
\hline $28 / 2 / 22$ & 6 & ., & ," & . & , & , & ,. \\
\hline $3 / 3 / 22$ & 9 &. & , & ,. & ", & $\because$ & ., \\
\hline $6 / 3 / 22$ & 12 & $"$ & ", & , & , & " & .. \\
\hline $10 / 2 / 22$ & 16 & , & ", & .. & 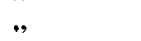 & $\because$ & , \\
\hline
\end{tabular}


The eggs are obviously much more resistant than the mites themselves and it is apparent from the discrepancy between Series I and II that a slight change in the conditions of carrying out the experiment may lead to failure. In view of this a fresh series of experiments (III) was set up, the results being shown in Table IV $b$, which also gives the action of Ammonia vapour on the eggs.

Table IV $b$.

Series III. Effect of Pyridine and Ammonia on Eggs of Cheese-mites.

Temp. of exposure $18^{\circ}-18^{\circ} \mathrm{C}$.

Exposure in flasks sealed with lead-lined stoppers.

Air of tleak seturated with vepour.

Time elapeing before examination is reckoned from time of taking ont of flaskg.

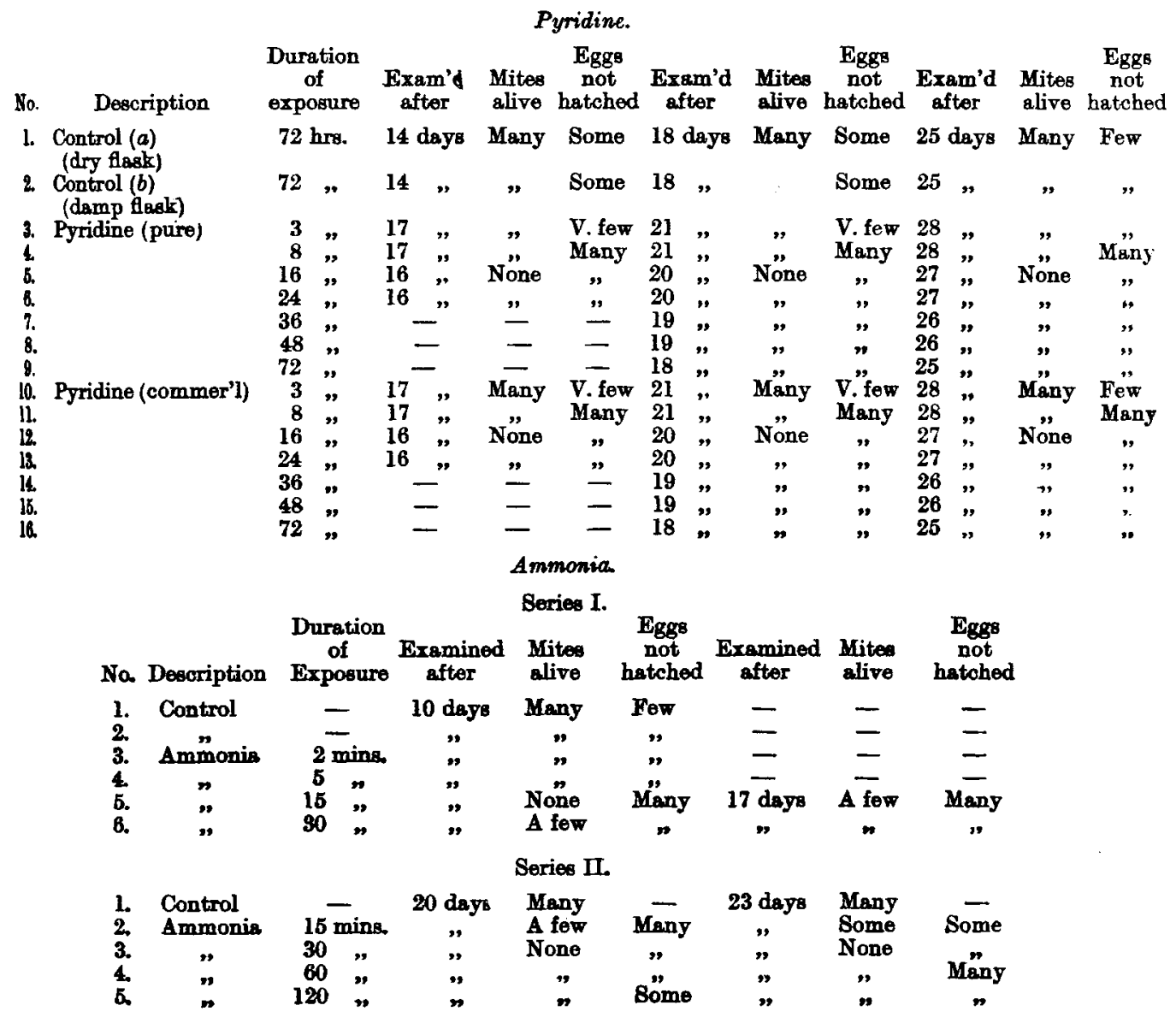


In Series III the lethal chambers were conical flasks of about 1200 c.c. capacity. Small samples containing many eggs and a few mites (100 to 28) were placed in small tubes, the mouths of which were covered with fine silk gauze, and suspended in the vapour in the flask at a temperature of $18^{\circ}-19^{\circ} \mathrm{C}$. for varying lengths of time. The flasks were hermetically sealed by lead-lined rubber stoppers. After exposure the samples were poured out into small flat dishes and exposed to the atmosphere for 15 to 30 minutes until the odour of Pyridine had almost disappeared. They were then placed in a large bell-jar containing a basin of water and left overnight, after which they were transferred to tubes with the addition of a little flour and kept at $18^{\circ}-19^{\circ} \mathrm{C}$. in a moist atmosphere.

Two samples of Pyridine, one practically chemically pure, the other labelled commercial, were tested in this way for times ranging from three hours, which is just long enough to eliminate the mites, to 72 hours. It is of interest to note that in every case except the controls, the samples became covered with a mat of fungus mycelium, indicating that little danger to fungus growth is to be feared from exposures up to 72 hours. Examination was carried out from time to time up to 28 days. Three hours' exposure was quite ineffective against the eggs, practically all hatching out in 16 days; 8 hours was partially successful as many eggs did not hatch in 20 days, while 16 hours and upwards completely prevented hatching out. No difference whatever could be detected in the lethal properties of the two samples of Pyridine. It is considered that if the treatment be carried out at an equable temperature of about $18^{\circ}-20^{\circ} \mathrm{C}$., $16-24$ hours' exposure should be sufficient to eliminate both mites and eggs. It is recognised, however, that there may be cases of heavy infestation when the vapour of Pyridine may not be able to permeate completely and where a second exposure after fourteen days might be advisable before subculturing.

\section{Action of Pyridine on Mites (Quantitative).}

An attempt was made to put the results on a quantitative basis. This was deemed advisable because of the rather surprisingly high toxicity of Pyridine in air saturated with its vapour and because materials like Aniline and Dimethylaniline which, from the work of Tattersfield and Roberts (3), were expected by us to have a higher toxic value in the vapour phase than Pyridine had proved of doubtful value. Pyridine, Ammonia and Aniline were therefore compared. For this purpose flasks of about 1100 c.c. capacity were fitted with lead-lined rubber stoppers, through which passed a glass rod turned to a hook at the lower end, to 
which could be attached a short test tube by means of wire. The first series of experiments was carried out in air saturated with the appropriate vapour. In the case of Pyridine and Aniline a few drops in excess of what was required to saturate the atmosphere were pipetted into the flasks. After a time sufficiently prolonged to allow of the air being saturated, the tubes containing the mites and closed at the top by a little silk fabric of very fine mesh, drawn tight and fastened firmly to prevent the mites from escaping, were inserted by attaching to the hooks and pushing the cork home. With Ammonia 5-10 c.c. of 880 material was poured in; in this case the toxic action is so rapid.as to render the silk fabric unnecessary. Two controls were used for each set of experiments. After varying lengths of time, in the case of Ammonia reckoned in seconds, the tubes were taken out and either examined immediately or after a time.

The method of examination and the time that should elapse before it is carried out were matters of considerable difficulty and need some consideration. It is necessary to count at least a hundred mites to obtain reliable results. Preliminary experiments showed olive oil to be the best medium in which to count the mites under the microscope as they remain alive in it for one to two hours and its clearing action is marked. Those mites which on careful examination showed no sign of movement were regarded as dead. If inspection be carried out immediately after exposure there is a possibility of mistaking temporary anaesthesia or stupefaction for death. Experience showed, however, that this difficulty was not very serious, for the poisons tested appear to act on the motor nerves and a mite once thoroughly incapacitated in this way seems rarely to recover. As a matter of fact, immediate examination gives an underestimation of the toxic action-but this can hardly be avoided. The dangers of allowing the material to stand overnight appear more serious as even when serated in open dishes it loses such toxic materials as Pyridine and Aniline only after a little time and at different rates owing to differences in their respective vapour pressures, during which time the poison continues to act. Moreover, in this treatment there is a danger of desiccation, and of some non-poisoned eggs hatching out.

The effect of Pyridine was tested in two ways. The examination in one case was carried out immediately. In the other the treated mites were aerated in the open till the characteristic odour had disappeared; they were then kept for a further sixteen hours in a moist atmosphere, after which they were examined. In the case of Ammonia examination was carried out immediately and after the lapse of an hour or two during 
Table V.

Toxicity of Ammonia ( $\left.\mathrm{NH}_{4} \mathrm{OH}\right)$, Pyridine and Aniline to Mites. Atmosphere saturated to chemical.

Vapour from Ammonia -880. Rxaminstion immediately aftar treatment.

$\%$ calculated on live mites in control

\begin{tabular}{|c|c|c|c|c|c|c|c|}
\hline \multicolumn{2}{|c|}{$\begin{array}{c}\text { Time of } \\
\text { expoeure }\end{array}$} & $\begin{array}{l}\text { No. } \\
\text { alive }\end{array}$ & $\begin{array}{l}\text { No. } \\
\text { dead }\end{array}$ & $\begin{array}{c}\% \\
\text { alive }\end{array}$ & $\begin{array}{c}\% \\
\text { dead }\end{array}$ & $\begin{array}{c}\% \\
\text { ative }\end{array}$ & $\begin{array}{l}\% \\
\text { deed }\end{array}$ \\
\hline \multicolumn{2}{|l|}{ Controls } & 90 & 10 & 90 & 10 & 100 & - \\
\hline A. 16 be & ecs. & 87 & 13 & 87 & 13 & $86 \cdot 6$ & $3 \cdot 4$ \\
\hline B. $32 \cdot 2$ & $n$ & 78 & 32 & $70 \cdot 9$ & $29 \cdot 1$ & 78.7 & 21.3 \\
\hline C. $46 \cdot 2$ & " & 72 & 38 & $65 \cdot 5$ & $34 \cdot 5$ & $72 \cdot 7$ & $27 \cdot 3$ \\
\hline D. 60.5 & $"$ & 172 & 138 & $55 \cdot 4$ & $44 \cdot 6$ & 61.5 & 38.5 \\
\hline E. 75 & $"$ & 51 & 306 & $14 \cdot 3$ & $85 \cdot 7$ & 16 & 84 \\
\hline F. 90 & ", & 44 & 384 & $10 \cdot 2$ & $89 \cdot 8$ & $11 \cdot 3$ & $88 \cdot 7$ \\
\hline G. 105 & " & 8 & 271 & $2 \cdot 8$ & $97 \cdot 2$ & $3 \cdot 1$ & 96.9 \\
\hline H. 120.5 & $n$ & 10 & 263 & $3 \cdot 6$ & $96 \cdot 4$ & 4 & 96 \\
\hline
\end{tabular}

Vapour of pure Pyridine. Fxamination immediately after treatment.

\begin{tabular}{|c|c|c|c|c|c|c|c|}
\hline Control & & 144 & 19 & 88.3 & 11.7 & 100 & - \\
\hline A. 30 & ains. & 118 & 31 & $79 \cdot 2$ & 20.8 & 90 & 10 \\
\hline B. 60 & " & 121 & 45 & $72-9$ & $27 \cdot 1$ & 82 & 18 \\
\hline C. 90 & " & 44 & 55 & $44 \cdot 4$ & $65 \cdot 6$ & 50 & 50 \\
\hline D. 120 & $"$ & 20 & 77 & $20 \cdot 6$ & $78-4$ & 23 & 77 \\
\hline E. 150 & " & 10 & 97 & $9-4$ & $90 \cdot 6$ & 10 & 80 \\
\hline F. 180 & $"$ & 1 & 130 & 0.77 & 99.23 & 1 & 89 \\
\hline G. 210 & $"$ & 1 & 106 & 0.94 & $90-06$ & 1 & 99 \\
\hline B. 240 & " & 0 & 113 & o & 100 & 0 & 100 \\
\hline
\end{tabular}

Vaponr from Ammonis -880. Framination 1-2 hrs after trostment.

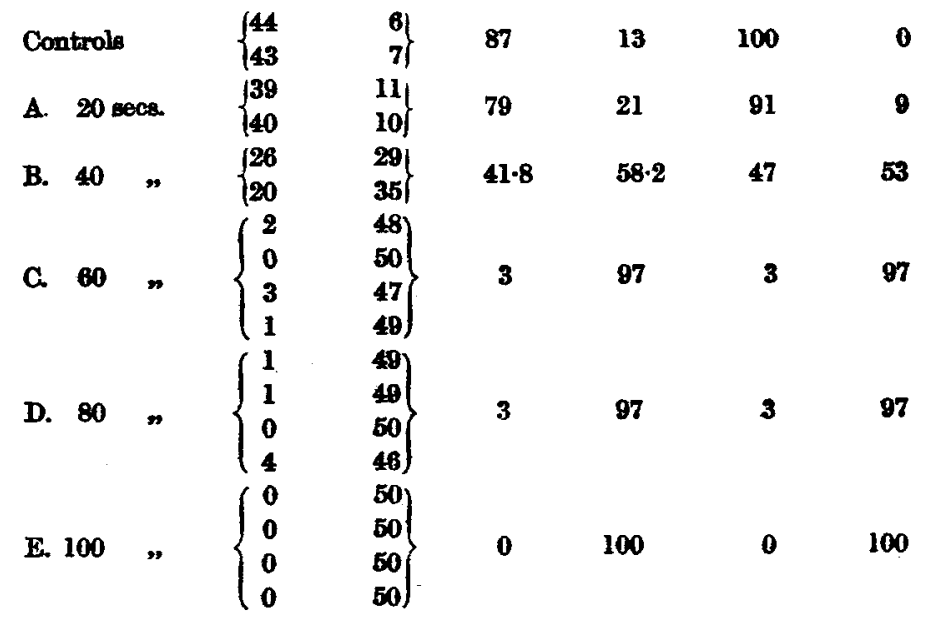




\section{Table V (contd.)}

Vapour of pure Pyridine. Examination after 16 hours.

\begin{tabular}{|c|c|c|c|c|c|c|c|}
\hline \multirow{2}{*}{\multicolumn{2}{|c|}{$\begin{array}{l}\text { Time of } \\
\text { Exposure }\end{array}$}} & \multirow[b]{2}{*}{$\begin{array}{c}\text { No. } \\
\text { Alive }\end{array}$} & \multirow[b]{2}{*}{$\begin{array}{c}\text { No. } \\
\text { Dead }\end{array}$} & \multirow[b]{2}{*}{$\begin{array}{c}\% \\
\text { Alive }\end{array}$} & \multirow[b]{2}{*}{$\begin{array}{c}\% \\
\text { Dead }\end{array}$} & \multicolumn{2}{|c|}{$\begin{array}{l}\% \text { calculated on live } \\
\text { mites in control }\end{array}$} \\
\hline & & & & & & $\begin{array}{c}\% \\
\text { Alive }\end{array}$ & $\begin{array}{c}\% \\
\text { Dead }\end{array}$ \\
\hline \multicolumn{2}{|c|}{ Controls } & $\left\{\begin{array}{l}50 \\
40\end{array}\right.$ & $\left.\begin{array}{l}5 \\
5\end{array}\right\}$ & 90 & 10 & 100 & 0 \\
\hline \multicolumn{2}{|c|}{ A. 7.5 mins. } & $\begin{array}{l}86 \\
189\end{array}$ & $\left.\begin{array}{l}18 \\
11\end{array}\right\}$ & $85 \cdot 8$ & $14 \cdot 2$ & 95 & 5 \\
\hline B. 15 & $"$ & 132 & 13 & 91 & 9 & 100 & 0 \\
\hline C. 22.5 & ", & 130 & 22 & $85 \cdot 5$ & $14 \cdot 5$ & 95 & 5 \\
\hline D. 30 & $"$ & $\left\{\begin{array}{l}81 \\
83\end{array}\right.$ & $\left.\begin{array}{l}32 \\
17\end{array}\right\}$ & 77 & 23 & $85-5$ & $14 \cdot 5$ \\
\hline E. 37.5 & $n$ & $\left\{\begin{array}{l}83 \\
85\end{array}\right.$ & $\begin{array}{l}17 \\
15\}\end{array}$ & 84 & 16 & 93 & 7 \\
\hline F. 45 & " & 45 & 55 & 45 & 55 & 50 & 50 \\
\hline G. 52.5 & " & 45 & 55 & 45 & 55 & 50 & 50 \\
\hline H. 60 & $"$ & 3 & 97 & 3 & 97 & 3 & 97 \\
\hline I. 67.5 & " & 7 & 98 & $6 \cdot 6$ & 93.4 & 7 & 93 \\
\hline J. 75 & ” & 6 & 94 & B & 94 & 7 & 93 \\
\hline K. $82 \cdot 5$ & ” & 6 & 94 & 6 & 94 & 7 & 93 \\
\hline L. 90 & $"$ & 0 & 100 & 0 & 100 & 0 & 100 \\
\hline
\end{tabular}

Vapour of pure Aniline. Examination immediately after treatment.

$\begin{array}{lrrrrrr}\text { Control } & 86 & 14 & 86 & 14 & 100 & - \\ \text { A. } 60 \text { mins. } & 81 & 19 & 81 & 19 & 94 & 6 \\ \text { B. } 120 \quad " & 43 & 57 & 43 & 57 & 50 & 50 \\ \text { C. } 180 \quad " & 5 & 95 & 5 & 95 & 6 & 94 \\ \text { D. } 240 \quad " & 2 & 98 & 2 & 98 & 2 & 98 \\ \text { E. } 300 \quad " & 1 & 99 & 1 & 99 & 1 & 99\end{array}$

which time the vapour had escaped. An inspection of Table $V$ and Fig. $1 a$ shows that immediate examination rather understates the effect of the poison. The proportion of live to dead mites was counted in both treated tubes and controls and the percentage of survivors in the tests to the live mites in the controls calculated. This percentage was plotted against time. The results are set out in Table V and Fig. $1 a$.

Fig. $1 a$ shows that air saturated with Pyridine is rather more toxic than when saturated with Aniline. This does not mean that weight for meight or molecule for molecule Pyridine is more toxic than Aniline; as the latter having a lower vapour pressure at ordinary temperatures $\left(15^{\circ}-18^{\circ} \mathrm{C}\right.$.) would saturate air with less of that material (weight for reight) in the vapour phase. The curves take the usual sigmoid form characteristic of such reactions. Henderson Smith (4) who studied the toxic action of Phenol on Botrytis spores obtained curves of a similar 


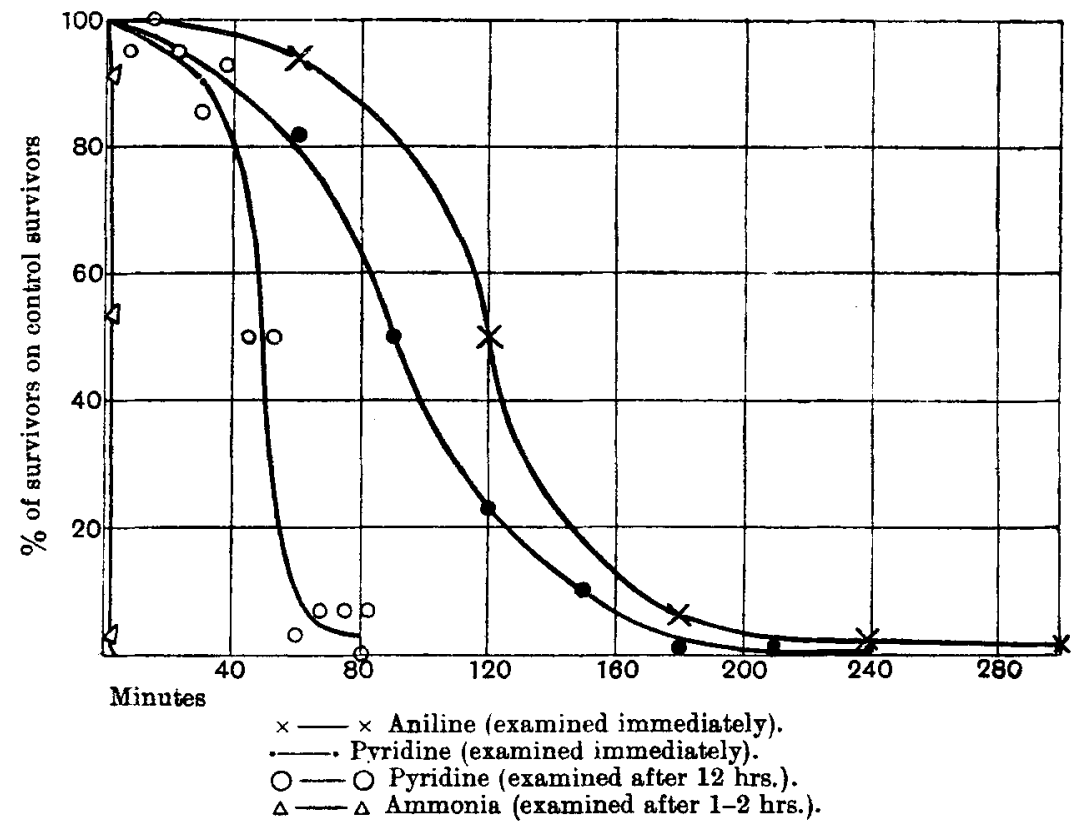

Fig. 1 a. Toxicity of vapours of Ammonia, Pyridine and Aniline to mites.

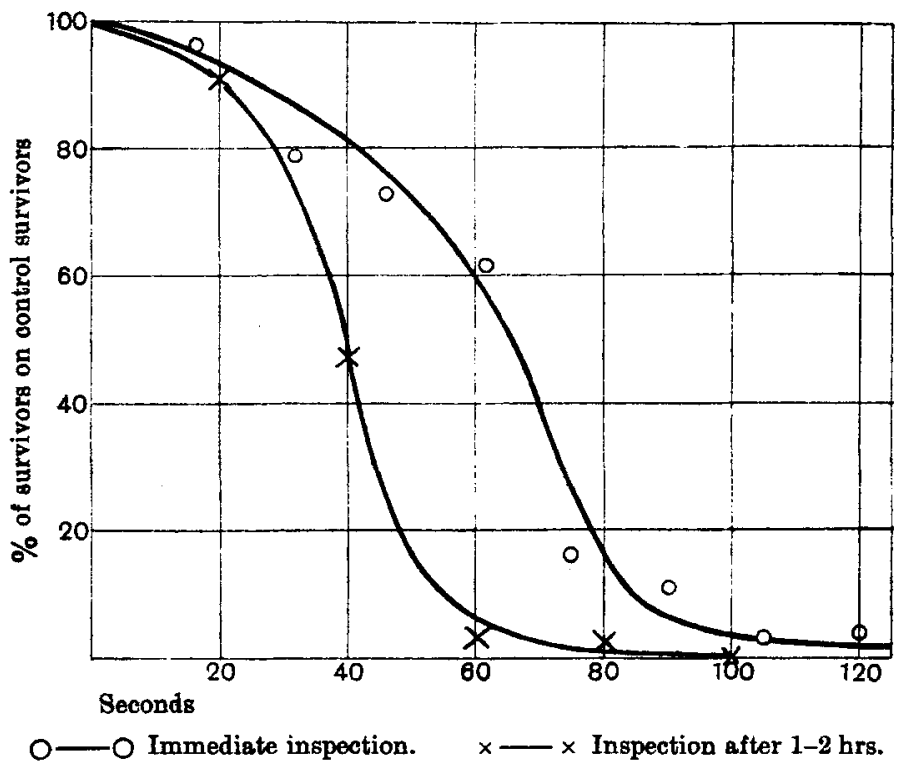

Fig. $1 b$. Toxicity of Ammonis vapour to mites. 
type, and showed that if the strength of the phenol be progressively. raised the curve approximates to the logarithmic type, but that both types of curve are explicable by assuming variations of resistance amongst the spores.

In our case, working at the saturation point of poison in air, a similar method was impossible, but even with so rapidly acting a poison as Ammonia the curve obtained was distinctly sigmoid in type when survivors were plotted against time expressed in seconds instead of minutes. Curves of this type would be expected in our case, where we have in an inseparable mixture, adult mites of various ages, larvae and nymphs. The distribution of the resistances varying in all three stages of development would be complex, and the variations so great that with the most highly toxic of materials the survival curve would be of the type obtained. The toxic action of Ammonia proved so rapid that it is not expressible with accuracy on the same scale as that of Pyridine and Aniline, and is put therefore on a second scale in Fig. $1 b$.

In view of the above results it seemed of importance to ascertain whether the considerable toxic action of Pyridine could be regarded as specific. Tattersfield and Roberts(3) showed that molecule for molecule Aniline in the vapour phase was about three times as toxic to wireworms as Pyridine. For this purpose minute but progressively increasing quantities of Pyridine or of Aniline were inserted by means of a graduated capillary pipette into calibrated flasks (1100-1200 c.c.) fitted with lead-lined rubber stoppers and glass hooks, and the cork inserted. When the material had evaporated, mites (about the same number in each case) were introduced in small test tubes closed by silk gauze and attached by wire to the hook and allowed to stand for a period of three hours. This time was convenient as permitting each set of tests to be comfortably finished in one day and as giving nearly 100 per cent. of deaths with a saturated concentration of Pyridine in air. The counts were made in the usual way. The results are shown in Table VI and percentages of survivors plotted against millionths of gramme-molecular concentrations of poison in a litre of air, in Fig. 2.

The curve for Pyridine is distinctly sigmoid in character, indicating that equal increases in concentration do not have a corresponding effect. An increase of dose from 30 to 50 millionths of a gramme-molecule shows little or no increase in toxic action, but an increase of from 50-70 accounts for 75 per cent. of the mites while further increases up to near the saturation point produce effects only very gradually. The curve for Aniline is not complete, as towards the lower end of the curve the flasks are 
saturated with vapour, the slowing down of the reaction being undoubtedly due to this cause.

\section{Table VI.}

Showing Toxic Effect of increasing doses of Pyridine and Aniline to Cheese-mites (T. longior).

Pyridine. Exposure 3 hours. Temp. $16^{\circ}-18^{\circ} \mathrm{C}$.

\begin{tabular}{|c|c|c|c|c|c|c|c|c|c|}
\hline & $\begin{array}{l}\text { Vol. of } \\
\text { flask } \\
\text { c.c. }\end{array}$ & $\begin{array}{c}\text { c.o. } \\
\text { added }\end{array}$ & $\begin{array}{l}\text { c.c. added } \\
\text { per } \\
1000 \text { c.c. }\end{array}$ & $\begin{array}{l}\text { Wt. per } \\
1000 \text { c.c. } \\
\text { of air }\end{array}$ & $\begin{array}{c}\text { Millionthe } \\
\text { of gm. mol } \\
\text { per } \\
1000 \text { c.c. } \\
\text { of air } \\
\text { (approx.) }\end{array}$ & $\begin{array}{l}\text { No. } \\
\text { alive }\end{array}$ & $\begin{array}{l}\text { No. } \\
\text { dead }\end{array}$ & $\begin{array}{c}\% \\
\text { alive }\end{array}$ & $\begin{array}{c}\% \text { alive } \\
\text { calculated } \\
\text { on live mites } \\
\text { in control }\end{array}$ \\
\hline $\begin{array}{l}\text { Control } \\
\text { A. }\end{array}$ & $\overline{1156}$ & $\overline{002}$ & .00173 &.$\overline{0017}$ & $\overline{21 \cdot 5}$ & $\begin{array}{r}117 \\
75\end{array}$ & $\begin{array}{l}34 \\
25\end{array}$ & $\begin{array}{l}\mathbf{7 7 \cdot 5} \\
75\end{array}$ & $\begin{array}{r}100 \\
97\end{array}$ \\
\hline B. & 1191 & .004 & .0033 & .0032 & 40 & 75 & 25 & 75 & 97 \\
\hline C. & 1172 & .006 & .0051 & .005 & 63 & 32 & 62 & 38 & 49 \\
\hline D. & 1192 & .008 & .0067 & .0066 & 83.5 & 14 & 91 & 13 & 17 \\
\hline E. & 1175 & .01 & .0085 & .0083 & 105 & 9 & 78 & 10 & 13 \\
\hline F. & 1178 & .012 & .01 & .0098 & 124 & 10 & 101 & 9 & 11 \\
\hline G. & 1169 & .014 & .012 & .0118 & 150 & 2 & 98 & 2 & 3 \\
\hline H. & 1183 & .016 & .0135 & -0132 & 167 & $\mathbf{3}$ & 89 & 3 & 4 \\
\hline I. & 1158 & .018 & .0155 & .015 & 190 & 0 & 90 & 0 & 0 \\
\hline
\end{tabular}

All the mites after treatment with Pyridine extremely sluggish, and appear paralyeed.

Aniline. Exposure 3 hours.

$\begin{array}{lrlllrrrrr}\text { Control } & - & - & - & - & - & 174 & 62 & 74 & 100 \\ \text { A. } & 1156 & .001 & .00086 & .00086 & 9 & 93 & 51 & 65 & 88 \\ \text { B. } & 1191 & .002 & .0017 & .0017 & 18 & 58 & 80 & 42 & 57 \\ \text { C. } & 1172 & .003 & .0026 & .0026 & 28 & 29 & 85 & 25 \cdot 4 & 34 \\ \text { D. } & 1192 & .004 & .0033 & .0033 & 36 & 32 & 130 & 20 & 27 \\ \text { E. } & 1175 & .005 & -0043 & -0044 & 47 & 27 & 143 & 16 & 21 \\ \text { F. } & 1178 & .006 & .005 & .005 & 54 & 22 & 137 & 14 & 19 \\ \text { L. } & 1167 & .018 & .015 & .0153 & 164 & 25 & 112 & 18 & 25\end{array}$

All the live mites after Aniline treatment more active than in case of Pyridine. All flasks saturated from D downwards before treatment. C doubtful.

On these curves the 50 per cent. survivor points correspond to 21 millionths of a gramme-molecule of Aniline and 63 of Pyridine, indicating that at this point, the most suitable one for purposes of comparison, Aniline is about three times as toxic as Pyridine. Taking the Aniline curve as a whole, the break towards the end due to the fact that from about 35 millionths of a gramme-molecule upwards the air is saturated with vapour, shows that its toxic inefficiency is not due to an intrinsic lack of poisonous properties, but that its low vapour pressure limits to this extent its concentration in air at ordinary temperatures. 
From a qualitative point of view Pyridine seems to have an entirely characteristic reaction. In the case of Aniline the survivors up to the 50 per cent. death point are fairly active. With Pyridine, however, from the smallest dose upwards the survivors are obviously seriously incapacitated; they appear to be suffering from motor paralysis and are only just capable of twitching mouth parts and legs. This unfortunately cannot be expressed graphically, but the condition is so marked as to indicate that Pyridine has a very powerful and possibly a specific toxic action on these pests. So small a concentration as .0017 c.c. in 1000 c.c. of air is

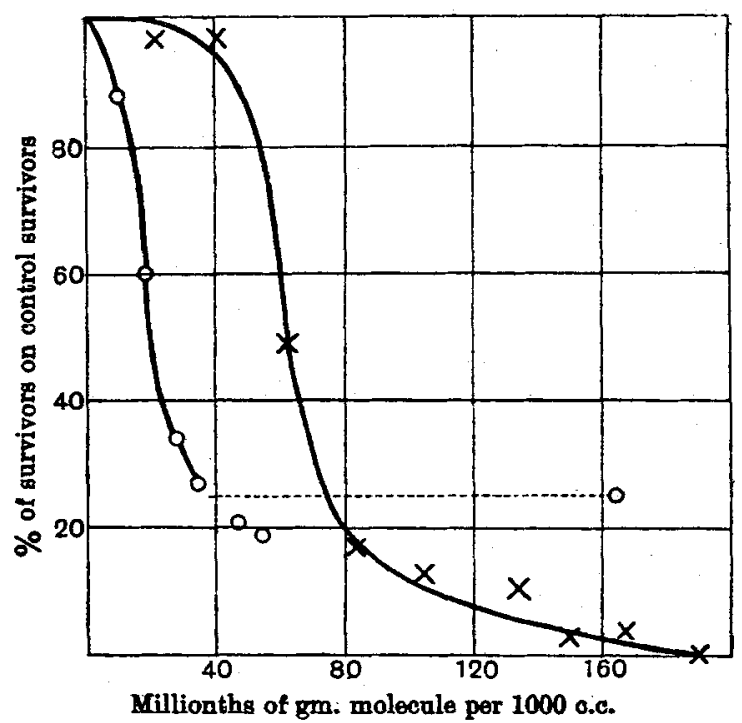

$x-x$ Pyridine. $0-0$ Aniline.... . Air saturated at close of experiment.

Fig. 2. Toxic effect on mites of increasing concentrations of the rapours of Pyridine and Aniline.

capable of almost completely paralysing in three hours nearly 100 per cent. of the mites.

\section{Toxic Efrect of Pyriding on Fungt.}

After preliminary trials had shown that Pyridine was successful in eliminating mites a large number of infected cultures were treated with the vapour of Pyridine overnight (16 hours). The infection consisted chiefly of $A$. farinae with a large number of eggs, some $T$. longior while several cultures of $M$ ucor were also infected with G. spinipes or $G$. cadavenum. The cultures were examined a week after treatment and there 
was no recovery of mites or hatching out of eggs. They were then subcultured on Czapek's agar and all the subcultures grew and were apparently unaffected by the Pyridine. The six cultures of Mucor were, however, contaminated with Penicillium. A possible explanation of this seems to be that the mite Glyciphagus, present only in these tubes, has long hairs capable of carrying Penicillium spores. The cultures treated were of species isolated from the soil and were as follows:

Mucor hiemalis (Wehmer), Botrytis pyramidalis (Sacc.), Johnson, Hormodendrum cladosporioides (Fres.), Sacc., Gliocladium penicillioides Corda (Icon.), Stachybotrys alternans Bonord., Monosporium sp., Fusarium, sp. 1, Fusarium, sp. 2, Penicillium, sp. 1, Penicillium, sp. 2.

Nine other unidentified species including one of the Sphseropsidales and a Dematiate form were also treated, the total number of cultures being 78. Since this experiment the method of treatment has been used a number of times and has been successful with one possible exception. In the latter case three cultures which had been treated were found some months later to be infected, but as they were among other newly infected cultures it was impossible to tell whether this was due to the failure of the original treatment or to re-infection. It was decided, in view of these results, to carry out a few quantitative experiments on the toxic effect (if any) of Pyridine to some common fungus, in order to ascertain how far this treatment could be carried with safety. The fungus chosen was Aspergillus niger, since work on the effect of Pyridine and various organic bases on this organism had been carried out by Brenner(b) and Lutz (6).

Into each of a series of conical flasks of 500 c.c. capacity, 200 c.c. of a suitable liquid medium was introduced, and sterilised. Gradually increasing amounts of pure Pyridine were added, and the flasks inoculated with 5 c.c. spore suspension. After a period the cultures were filtered, thoroughly washed by decantation, dried and weighed. After some preliminary experiments Coons' solution containing double the amounts of all the ingredients was decided upon as giving in a reasonable time a yield of a suitable amount for both washing and weighing purposes 1 .

The most rapid and efficient filter was a Gooch crucible used with a pad of cotton-wool and under a not too high vacuum. The Gooch

2 The medinm contained in 1000 c.c

$\begin{array}{llll}\text { Magnesium sulphate } & \ldots & \ldots & \mathbf{0 . 9 8 6}\end{array}$

Potass bi-phosphate $\ldots \quad \ldots \quad \mathbf{2 . 7 2 0}$

$\begin{array}{llllll}\text { Asparagin } \quad \ldots & \ldots & \ldots & \mathbf{0 . 5 3 0}\end{array}$

Maltose $\quad \ldots \quad \ldots \quad \ldots \quad$ 7.200. 
crucibles and fungus were then dried for 24 hours at $70^{\circ} \mathrm{C}$. and finally at $90^{\circ}-100^{\circ} \mathrm{C}$. to constant weight.

The technique of the method has not yet been completely studied by us, but it proved of sufficient accuracy for the purpose of this investigation. Experiment No. 1 was carried out on an Aspergillus sp. isolated from an onion. The cultures were incubated at $26^{\circ} \mathrm{C}$. for a period of seven days. Table VII shows that the growth of this fungus is not inhibited until a concentration somewhere between $\cdot 318$ and $\cdot 636$ per cent. of Pyridine is reached.

Table VII.

Effect of Pyridine on Aspergillus niger.

Culture solution Coons' double strength 200 a.c. Temp. $26^{\circ} \mathrm{C}$.

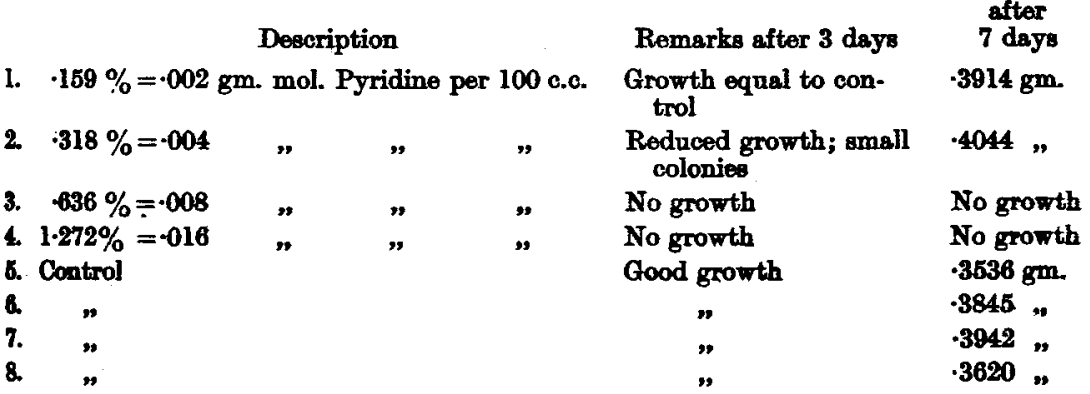

It was desirable to ascertain whether the toxicity of Pyridine was due to its possessing basic properties either acting directly or indirectly by its effect upon the $p \mathrm{H}$ value of the medium. Two sets of flasks were used. One set contained gradually increasing doses of pure Pyridine as in the previous experiment, but in this case starting with $\cdot 318$ per cent. of this compound (=.004 gm.-mol. per $100 \mathrm{c.c}$.) and working up by smaller increases to 636 per cent. The quantities of Pyridine in the second set exactly tallied with those in the first except that before addition the Pyridine solution was brought to a $p \mathrm{H}$ value of about 4.7 (the same as the medium) by the addition of appropriate amounts of standard sulphuric acid. The culture of Asp. niger used was one kindly given to us by the Pure Culture Laboratory at the Lister Institute, No. 594, grown on Czapek's medium and about 7 days old. It proved, unfortunately, rather more susceptible to poison than the one used in the previous test. After inoculation the flasks were set aside in a dark cellar, the temperature of which remained somewhere between $18 \cdot 5^{\circ} \mathrm{C}$. and $19 \cdot 5^{\circ} \mathrm{C}$. Recourse was had to a rather lower temperature as there 
appeared to be some escape of Pyridine when the cultures were incubated at $25^{\circ} \mathrm{C}$. The yields were weighed after a period of three weeks. An imepection of Table VIII brings out with startling clearness the large differences in yield that ensue through the minimising of the toxic effect of Pyridine by the addition of amounts of acid in quantities sufficient partially to neutralise the base.

\section{Table VIII.}

Toxicity of Pyridine to Aspergillus niger.

Cultare solution Coons' doable strength.

Pure Pyridine B.G. 983 added.

Cultare and organizm. Aepergillus niger from Lister Inot. No. 594.

Period of incubation 21 days.

Temperatare of incubation $18^{\circ}-19^{\circ} \mathrm{C}$.

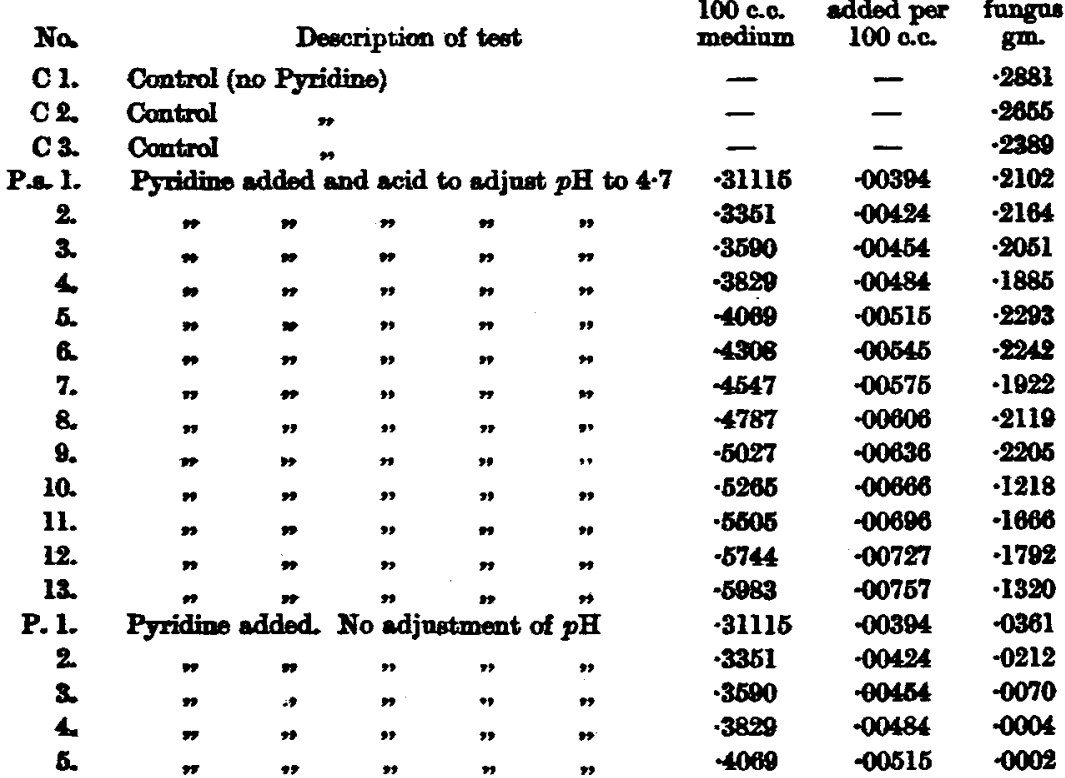

As we wished to trace the toxic action of Pyridine completely, and as these results indicated that our initial additions of Pyridine were too lange, a fresh series of experiments was set up commencing with an extremely small dose (about 005 per sent.) and ranging up by small additions to concentrations that experience showed were sufficient to inhibit growth completely. The greatest care was taken to ensure that 


\section{Table IX.}

Toxicity of Pyridine to Aspergillus niger.

Soriow III. Cultum modium Coons' double strength 200 c.e.

Pure Pyridine (S.G. =-982) added trom capillary pipette.

Culture and onganiam Aspergillus niger from Lister Inst. No. 694. Subculture on Coons' agar.

Ago of oultwre 20 days. Inconlated in 5 c.c. sterile water.

Time of inoubetion 21 days.

Temperuture of incubation $18^{\circ}-19^{\circ} \mathrm{C}$

Tield after the addition of atendard soid to

Gm. Pyridine Gm. Pyridine

c.c. of per 100 c.c. per 100 c.c. Mean gm. Pyridine (originally found at end No. per 205 c.c. added) of expt.

Pyridine

1. 01

$-0048$ per 100 c.e.

neutralise

2. 05

$-024$

.024

.048

.047

4. .15

$-073$

.095

$\overline{006}$

6. .25

.119

.143

.167

-

7. 3

.191

.136

9. 4

$10 . \quad .46$

.219

.20

.235

.208

.200

.257

.248

.282

.270

.305

.283

.329

.285

.351

$-329$

.373

.326

.398

.367

(.0048)

Gm. yield

16. $\quad .738$

.781

.421

$-445$

$(\cdot 3845)^{1}$

.024

of tungus

ro-inoculated

19. .784

20. .034

.468

-

-

.048
$(-073)$

$.073)$

(-119)

$-139$

(-167)

-195

.213

.222

.252

.276

.294

.307

$-340$

.349

.382

.5074

.4817

.4887

$\begin{array}{r}4717 \\ \hline\end{array}$

$$
.4674
$$

.4885

.4644

$$
.4676
$$

.3890

.4540

.2699

.2103

.0862

.0218

.0152

.0091

.0034

Treces

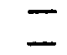

-

1. 984

$-491$

.515

.530

$=$

$-$

No growth

.4857

$-5185$

$=$

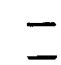

$=$

$x$

,

.5124

.6042

.6560

.5250

.561

.585

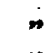

$-4957$

$\overline{(\cdot 558)}$

-

.608

$\bar{z}$

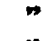

.5346

.4811

28. Control 1

$=$

.5004

.5229

Mean

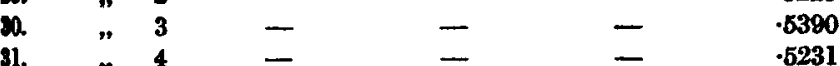

.5404

32. " $\begin{array}{cccc}4 & - & - & -\end{array}$

.5568

1 Determined after neutraliation of Pyridine by acid and allowing fungus to grow - f.rther tinree weeks.

Controls gave a precipizate with Iodine in Potass. Iodide equal to 0025 per cent. atine. Thin was allowed for. 
each lot of medium should be treated in the same way during sterilisation so that no variations in dilution should take place. The flasks were as far as could be judged of the same size and the cotton-wool plugs rolled in the same way and fitting as nearly as possible the necks of the flasks with an equal tightness. Pyridine was added from a capillary pipette, and the flasks inoculated and incubated as in previous series at $18.5^{\circ}$ $19.5^{\circ} \mathrm{C}$. for a period of 21 days.

At the end of this period they were filtered and after careful washing and drying the yields obtained were weighed. A portion of the filtrate was set aside and the Pyridine estimated by the method of Harvey and Sparks (7) which we had found to give results of fair accuracy. As the medium itself gave a precipitate with Iodine solution in Potassium

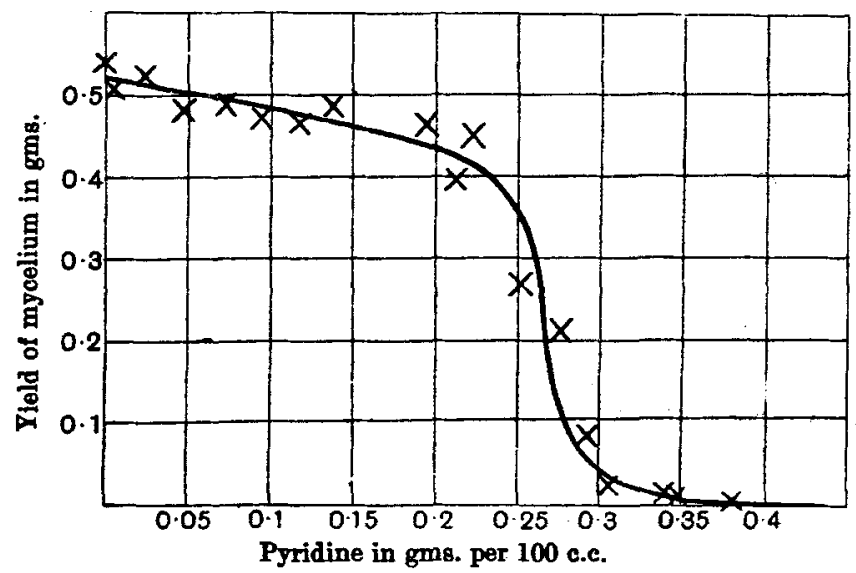

Fig. 3. Toxicity of Pyridine to Aspergillus niger.

Iodide, a blank estimation was done on the controls and the amount deducted from that found in the tests. We were thus able to ascertain whether the concentration of Pyridine remained the same throughout. the experiment. The means of the amounts of Pyridine added initially and found at the end were taken and plotted against the yields, the curve being drawn freehand through the points.

Table IX and Fig. 3 show that the toxic effect of Pyridine is at first very gradual, the growth yields diminishing very slowly up to a concentration of -225 per cent. The inhibitive effect of the base from that point onward is, however, increasingly marked and the yields diminish rapidly with small increases in the concentration of Pyridine until at a strength of $\cdot 325$ per cent. they are almost negligible after which the curve of growth yields tails off very gradually, thus taking a sigmoid shape. 
This result corresponds with that obtained by Henderson Smith (4) in his work on the toxic action of phenol on Botrytis spores and it seems probable that a similar explanation should be given in this case, i.e. one based upon the variation in resistance of the fungus spores. If it is assumed that this variation is normal and that the spores could be graded according to resistance, then successive grades would contain numbers of spores rising to a maximum in the middle grades and falling again in the last grades. Thus with each successive dose of Pyridine successive grades of spores would fail to germinate. It follows that the middle of the curve is steepest, since with these doses the largest numbers of spores are either killed or their growth inhibited. The toxic effect of the addition of small doses of Pyridine is therefore at first slight then rises to a maximum and falls again as higher concentrations are reached1.

Table X.

Comparison of Effect of Pyridine and Caustic Soda on growth of Aspergillus at the same $\mathrm{pH}$ values.

\begin{tabular}{|c|c|c|c|c|}
\hline No. & Base added & $\begin{array}{l}\text { Wt. of bace } \\
\text { contained in } \\
100 \text { c.o. of } \\
\text { medium }\end{array}$ & pH value & $\begin{array}{l}\text { Gm. yiald of } \\
\text { fangus }\end{array}$ \\
\hline 19. & Pyridine & $.429 \cdot \mathrm{gm}$ & $6-45$ & No growth \\
\hline 21. & " & $.476 "$ & 6.5 & $"$ \\
\hline 23. & " & $.524 "$ & 6.52 & ", \\
\hline 25. & 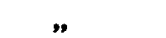 & .671, & $6 \cdot 55$ & 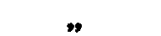 \\
\hline 5. & Canstic sods & $016 "$ & 6.45 & .4808 \\
\hline 6. & " & .018 & 6.5 & .4644 \\
\hline 7. & $"$ & $.019 "$ & 6.52 & +4792 \\
\hline 8. & $"$ & $.020 "$ & $6 \cdot 56$ & .4823 \\
\hline C 1. & Control & - & $4 \cdot 75$ & .4553 \\
\hline C 2. & , & - & $4 \cdot 75$ & .4345 \\
\hline
\end{tabular}

I As the medium used was slightly acid ( $\mathrm{pH} 4 \cdot 45-4 \cdot 75$ ) it might be considered that at the lower concentrations of Pyridine its toxicity might be seriously lecsened by partial nentralisation. Mr E. M. Crowther kindly determined for us the effect upon the $p H$ value of our medium of progressively increasing additions of Pyridine and so the amounts of undisecoiated base present. With an addition of $.01 \mathrm{gm}$. of Pyridine to 100 c.0. of medium 53 per cent. was present as free bese, while additions from 1 to $\cdot 9 \mathrm{gm}$. to 100 c.c. of modium gave amounts of free undissociated Pyridine ranging from 82-92 per cent. of the amounts added. The effect upon the curve is to displace it slightly to the left, but not fundamentally to alter its character. We are aware of the fact that Aspergillus niger may during growth give rise to notable amounts of acid and that in tracing out an accurate graph of the toricity of Pyridine to this fungus the amounts of free base before and after the experiment should be determined. This, however, was outaide the seope of these prelininary experimenta, which were intended to ascertain to what extent a common fungue could tolerste this base when added to 8 oynthetic modinm. 
As previously stated it was considered that these results might be due to the alteration in $p H$ values of the medium on the addition of Pyridine. The medium used has a $p H$ value of about $4 \cdot 75$, which the addition of 4229 per cent. of Pyridine brought up to 6.45 . To test this point a series of experiments was set up in which the $p H$ 's of the medium were adjusted by means of $N / 10$ Sodium Hydrate to those obtained in the flasks in which the higher concentrations of Pyridine inhibited growth. It will be seen from Table $X$ that the effect of incressing the $p H$ from 4.75 to 6.55 is very small. The alteration of $p H$ plays, therefore, an insignificant part. One other interesting point arising from these experiments is that the effect of Pyridine is to inhibit the germination of the spores rather than to kill, at any rate all of them, outright. After the yields in Series III, Table IX, had been weighed, additions of standsrd sulphuric acid were made to the flasks $21-27$ where no growth was visible: within two days the spores in these flasks had begun to germinate and growth took place at a rapid rate. After standing for three weeks the yields were weighed, the results being set forth in the last column of Table IX. They are of the same order as those given by the controls during the previous three weeks. At the end of this period the Pyridine remaining in two of the experiments (19 and 27) was determined. The amounts found are expressed in brackets in column 4 .

Lutz (6) has stated that in the presence of some other form of assimilable nitrogen, Pyridine may act as a food to fungi. Although our experiments were not set up to investigate this point and must not be regarded as final, for this particular fungus (Aspergillus niger) we have not obtained any evidence of Pyridine acting as a stimulant to fungal growth. However small an addition of this base might be made there has never been shown an increase in the yield which could be considered outside the margin of error of the experiment. There is undoubtedly towards the end of the series in Table IX a loss of Pyridine, which however cannot be accounted for by assimilation, being probably due to volatilisation as it is greater as the amount of growth diminishes. Moreover, the deficiency in the amount of Pyridine found after its neutralisation and allowing the Aspergillus to grow for a further three weeks is of the same order as that found in the flasks where at the end of three weeks and before neutralisation the growth had been small.

The amount of Pyridine absorbed by culture media from an atmosphere ssturated with its vapour is about 4 per cent. in sixteen hours. This is much more than a toxic dose. Subculturing after treatment, especially of fungi growing in liquid media, is therefore essential. 


\section{Discussion of Results.}

Toxicity of Pyridine and Ammonia to Mites.

Pyridine is shown to have a considerable toxicity. to mites and while its effect upon fungi (in the small doses necessary to kill mites) is practically nil, in continually increasing doses it becomes more marked until a concentration is reached at which germination and growth are completely inhibited. The toxicity to mites is surprising as it has generally been assumed that the toxicological action of Pyridine to all living organisms is not marked.

Pyridine and the various monacid ammonium bases have been the subject of considerable toxicological research, either because of their occurrence as groups in the molecular structure of many well-known and widely used alkaloids (e.g. Nicotine) or because of their close similarity to them in physiological action.

Brunton and Tunnicliffe(8) have shown that on frogs, Pyridine has, in relatively small doses, a general narcotic action, that its paralysing action on motor nerve endings is of the slightest and that its action is almost wholly confined to the sensory part of the nervous system. They came to the conclusion that Pyridine, compared with its derivatives, is not an active poison, a conclusion that would hardly be expected when the very marked stability of Pyridine is borne in mind. From its close relationship chemically to Nicotine, one would expect a fairly high insecticidal value, yet Pyridine has proved itself of little use in this respect.

Fryer (9) states that after a large number of tests the results have proved in all cases disappointing. The Entomologist to the United States Dept. of Agriculture(10) confirms this and reports that while the compounds most highly poisonous to insects are to be found among the organic nitrogen derivatives the toxic value of Pyridine is small. Tattersfield and Roberts (3) found that to wireworms, Pyridine was less potent as an insecticide than any other of the organic bases tested.

Although the present results do not definitely prove that Pyridine is a compound of high specific toxicity to mites, they do indicate that it possesses a toxic action which is much greater than experience would lead us to expect. We were only able to compare it critically with Aniline, a comparison which led to the conclusion that the low vapour pressure of the latter compound tended to put a limit on its toxicity, but that molecule for molecule in the same time it was more poisonous from a quantitative point of view than Pyridine. On the other hand in very minute doses Pyridine had a most profound narcotic effect, inhibiting all the larger movements and leading to almost complete paralysis. 
The great toxic action of Ammonia is not surprising, for it is natural to expect such a strongly irritant substance to be highly poisonous to lower forms of animal life.

\section{Toxicity of Ammonia and Pyridine to Fungi.}

The toxicity of Pyridine to lower forms of plant life has been the subject of some investigation. The views expressed although somewhat discrepant generally lean towards the opinion of its comparatively low toxic properties. Morgan and Cooper(11) state that of many monacid organic bases they tested the bactericidal properties of Pyridine were the least. Lutz (6) has stated that it may act under certain conditions as a food, a conclusion not borne out by the experiments described above, but it must be recognised that very special conditions as to media and organism may be required for the feeding effect of Pyridine to manifest itself.

Our experiments do not definitely indicate the position of Pyridine in the toxic scale as far as fungi are concerned, but we lean to the view that it is not high. This is not easy to understand, for the compound is inert and its basic properties weak. The latter fact, if the views of Newton Harvey (12) are correct, should indicate a rather high toxicity. This investigator points out that weak bases penetrate cell walls with greater rapidity than strong bases such as Caustic Soda, and that penetration is of the first importance in determining toxicity. On the other hand, another important and countervailing factor is dissociation, the least dissociated bases being least toxic.

As Pyridine is a weak base and very slightly dissociated its toxic properties might be low despite its penetrating power. It is outside the purview of the present investigation to explore this problem, but the rate of penetration of cell walls by chemical compounds is one of fundamental importance in the consideration of fungicidal and insecticidal problems and further investigation along these lines is contemplated. Our results show that fairly high doses such as $\cdot 5-6$ per cent. of Pyridine may inhibit germination and growth, and it is probable, although no proof is here advanced, that this is due to the Pyridine readily permeating the cell. These spores, however, will grow if the base is neutralised by acid, the Pyridine in all probability diffusing out of the cell with readiness as soon as the diffusion gradient is modified in a reverse way by the addition of the acid. Our experiments show that what little toxic properties Pyridine may have, it possesses chiefly in virtue of its basic nature. Its salts are hardly poisonous at all either because the acid ion prevents the migration and penetration of the cell wall by the pyridineum ion, or if the salt of Pyridine does penetrate its toxic properties within 
the cell are very slight. The toxicity of Pyridine does not arise out of its modification of the $p \mathrm{H}$ value of the medium but would seem in some way to depend upon a special relationship of the cell to the Pyridine molecule as a base.

\section{Practical Application of Method.}

The following method has been used in the treatment of mite infested fungus cultures with Py ridine. A large bell-jar of about 20 litres capacity is inverted and in the bottom is placed a flat dish containing about 20 c.c. of commercial Pyridine and covered by a wire gauze. The infested cultures, without removing the cotton-wool plugs, are placed in the bell-jar for 16 hours (overnight) and the jar is closed with a glass plate which should be luted down with clay or plasticine. Subcultures taken from the tubes after the above treatment have proved free from the infesting mites, except in one example described above, where some eggs appear to have survived the above treatment, so that in the case of very bad infestations or in very cold weather it may be advisable either to expose the tubes for 48 hours or to give two exposures of 16 hours duration separated by a period of fourteen to sixteen days. The latter method allows any unkilled eggs to hatch, the very susceptible larvae being rapidly poisoned by the second exposure to the vapour of Pyridine. Owing to the rather disagreeable odour of Pyridine it is advisable to carry out the treatment either in a good fume cupboard or outside the laboratory.

Strong Ammonia can be used for cleaning out laboratory apparatus. Its toxic properties to mites are exceedingly great, but as it has a slight but definitely deleterious effect upon some fungi, it is advisable to limit its use to apparatus when its vapour will not play for any prolonged period upon mycological cultures.

Our best thanks are due to Mr H. M. Morris, M.Sc., for much valuable advice and for identifying the species of mites, and to Mr E. M. Crowther, M.Sc., for the determination of the $p H$ values of our media.

\section{Summary and Conclusions.}

1. Mites are a serious pest of fungus cultures. The species that most frequently occur are Aleurobius farinae and Tyroglyphus longior with an occasional infestation with Glyciphagus cadaverum.

2. They can be controlled by exposing the cultures to the vapour of Pyridine, after which treatment the fungi can be subcultured safely. An exact description of the application of the method is given on p. 239 . (Commercial Pyridine is as effective as the pure material.) 
3. If these pests occur in laboratory apparatus they can be elixinated by the application of atrong Ammonia. Ammonia and its vapour are very rapidly effective against mites, but they should not be allowed to come into contact with cultures of fungi for too long a period of time in too high a concentration.

4. Pyridine is shown to have a elight toxic action to fungi, and to inhibit growth completely in certain concentrations which, however, are not at all likely to be objectionable in practice, especially if the treated cultures are subcultured.

5. A brief analysis of the toxic action of Pyridine on both Mites and Fungi is given.

(a) In the case of Mites minute doses have so powerful a paralysing action as to render it probable that Pyridine is specific in its toxic effect to these pests.

(b) In the case of Fungi, the action of Pyridine upon the germination and growth of Aspergillus niger was closely studied. It is shown that up to about $\cdot 25$ per cent., Pyridine has apparently very little toxic action and no feeding effect, but that above this concentration the toxicity increases with great rapidity. It is shown, however, that the toxic action is one of inhibition of germination and that the neutralisation of the base up to $0-6$ per cent., the highest concentration tested by us (even though spores have been exposed to its action for three weeks), permits growth to take place rapidly. Pyridine acts chiefly as a poison through its basic properties but not by the change in the $p H$ of the medium which ensues on its addition.

\section{REFERENCES.}

(I) Eales, N. B. (1917). Ann. App. Biol. Iv. 29.

(2) Nrwstead, R. and Duvali, H. M. (1919). Rev. App. Ent. A7, 91.

- (1918). Roy. Soc. Rept. of Grain Pests (War) Comm. No. 2.

(3) Tattkesfikld, F. and Roblarts, A. W. R. (1920). J. of Agr. Sci. x. 199.

(4) Henderson SmTth, J. (1921). Ann. App. Biol. vill. 27.

(5) BrenNern, W. (1914). Centr. Bakt. Abt. 2, Bd. 40,555.

(6) LuTz, L (1905). Bull. de la Soc. Bot. de France, wll. 194.

(7) HarVEr, T. F. and Sparks, C. F. (1918). J. Soc. Chem. Ind. xxxvir. 41 T.

(8) Brunton, T. L. and Tunncumrre, F. W. J. Physiol. xvir. 272.

(9) Fryme, P. J. (1920). Insect Pest and Fungus Diseases (p. 445).

(10) Rept. of the Entomologist U.S. Dept. of Agriculture, Washington, Aug. 1, 1921.

(11) Morgar, G. I. and Cooper, E. A. (1912). 8th Inst. Congr. of App. Chem. xIx. 243.

(12) Newton Harvey, E. Publ. Carnegie Inst. of Washington, No. 183, p. 131. 